\title{
パルスレーザー堆積法により
}

作製したアルミドープ酸化亜鉛透明導電膜の超薄膜化*

中村 真貴*1 ·生田 公洋*1 · 青木 孝憲*1

鈴木 晶雄 $* 1 \cdot$ 松下 辰彦 $* 1 \cdot$ 奥田 昌宏 $* 2$

\section{Ultra Thin Al-doped Transparent Conducting Zinc Oxide Films Fabricated by Pulsed Laser Deposition Method}

\author{
Masataka NAKAMURA*1, Kimihiro IKUTA*1, Takanori AOKI*1, \\ Akio SUZUKI*1, Tatsuhiko MATSUSHITA*1 and Masahiro OKUDA*2
}

${ }^{* 1}$ Department of Electronics, Information and Communication Engineering, College of Engineering, Osaka Sangyo University, 3-1-1 Nakagaito, Daito, Osaka 574-8530, Japan

*2Okuda Technical Office, 1-2-27 Mozu-Umemachi, Sakai, Osaka, 591-8032, Japan

(Received November 15, 2007, Accepted April 5, 2008)

\begin{abstract}
Approximately 20 110 nm-thick Al-doped transparent conducting zinc oxide (AZO) films have been deposited on glass substrates at temperature of $200 \sim 300^{\circ} \mathrm{C}$ by pulse laser deposition (PLD) using $\operatorname{ArF}$ excimer laser $(\lambda=193 \mathrm{~nm})$. When fabricated at the substrate temperature of $260^{\circ} \mathrm{C}, 40 \mathrm{~nm}$-thick AZO films showed the lowest resistivity of $2.61 \times 10^{-4} \Omega \cdot \mathrm{cm}$.
\end{abstract}

\section{1. はじめに}

透明導電膜は, 液晶テレビやプラズマテレビなどのフラッ トパネルディスプレイや太陽電池の透明電極として多く用い られており，材料には酸化インジウム錫（ITO）が使われて いる. しかし, 近年フラットパネルディスプレイが急速に普 及したため, ITOの主要材料であるインジウム（In）の枯 渴問題が懸念されている1-2). また最近では, ITO 粉末の毒 性についても問題視されている. そこでITOの代替材料と して資源が豊富で安価な酸化亜鉛 $(\mathrm{ZnO})$ が注目されている. 現在, ITO は超薄膜領域と呼ばれる膜厚 $50 \mathrm{~nm}$ 以下でも使 用可能であるが， $\mathrm{ZnO}$ 系透明導電膜では $150 \mathrm{~nm}$ 以下で急激 に特性が悪化する ${ }^{3)}$. その理由として島状構造から連続膜に 移行するのに $50 \mathrm{~nm}$ 以上の膜厚が必要となるため, 膜表面が 粗くなり電気的特性が悪化することなどが挙げられる. 我々 は以前より，ArF エキシマレーザー（波長 $193 \mathrm{~nm}$ )を用い たパルスレーザー堆積法 (Pulsed Laser Deposition: PLD) によりガラス基板上に $\mathrm{ZnO}$ 系透明導電膜を作製したことに ついて報告してきた ${ }^{4-9)}$. 今回は, 材料に $\mathrm{ZnO}$ に酸化アルミ ニウム $\left(\mathrm{Al}_{2} \mathrm{O}_{3}\right)$ を数\%添加した $\mathrm{AZO}$ を用いて超薄膜領域 での作製を行った。

\section{2. 実験条件}

Fig. 1 に AZO 透明導電膜の作製に用いた PLD 法の概略 図を示す。成膜条件を Table 1 に示す。 ArF エキシマレー ザー（波長 $193 \mathrm{~nm} ）$ を用い, レーザーエネルギー密度を 1.2 $\mathrm{J} / \mathrm{cm}^{2}$, 繰り返し周波数を $10 \mathrm{~Hz}$ ，基板をCorning\#7059ガラ

* 平成 19 年 11 月 15 日 第 48 回真空に関する連合講演会で発表 (15P-20)

*1 大阪産業大学工学部電子情報通信工学科 (⿳亠千 574-8530 大阪府 大東市中垣内 3-1-1)

*2 奥田技術事務所 (一591-8032 大阪府堺市百舌鳥梅町 1-2-27)
ス基板, 到達真空度を $10^{-4} \mathrm{~Pa}$, 酸素雲团気圧を $0 \mathrm{~Pa}$, 基 板ーターゲット間距離を $40 \mathrm{~mm}$, 基板温度を $200 \sim 300^{\circ} \mathrm{C}$, 膜 厚を20〜110 nm まで变化させ実験を行った. ターゲットは PC 制御により回転運動させ, レーザービームが 1 ヶ所に集

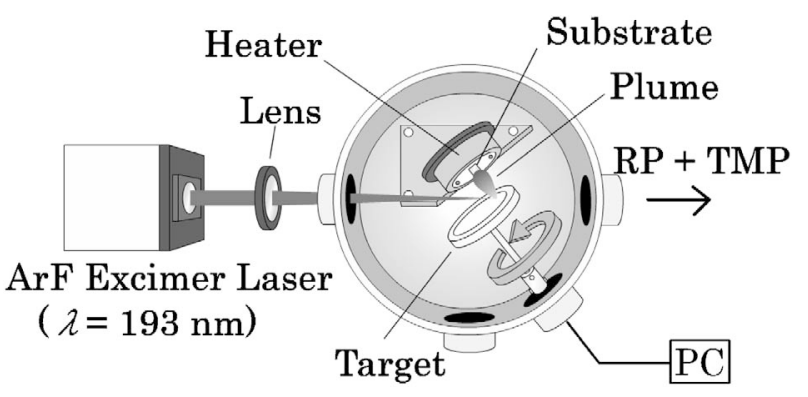

Fig. 1 Illustration of pulsed laser deposition system for AZO films using ArF excimer laser.

Table 1 Preparation conditions.

\begin{tabular}{|c|c|c|}
\hline Laser & \multicolumn{2}{|c|}{$\begin{array}{c}\text { ArF Excimer Laser } \\
\quad(\lambda=193 \mathrm{~nm})\end{array}$} \\
\hline Laser Energy & \multicolumn{2}{|c|}{$60 \mathrm{~mJ}$} \\
\hline Laser Energy Density & \multicolumn{2}{|c|}{$1.2 \mathrm{~J} / \mathrm{cm}^{2}$} \\
\hline Repetition Frequency & \multicolumn{2}{|c|}{$10 \mathrm{~Hz}$} \\
\hline Target & \multicolumn{2}{|c|}{$\mathrm{AZO}\left(\mathrm{Al}_{2} \mathrm{O}_{3}: 1.5\right.$ wt.\% $)$} \\
\hline Substrate & \multicolumn{2}{|c|}{ Corning \#7059 } \\
\hline Target to Substrate Distance & \multicolumn{2}{|c|}{$40 \mathrm{~mm}$} \\
\hline Base Pressure & \multicolumn{2}{|c|}{$\sim 10^{-4} \mathrm{~Pa}$} \\
\hline Gas Pressure & \multicolumn{2}{|c|}{$0 \mathrm{~Pa}$} \\
\hline Substrate Temperature & $200 \sim 300^{\circ} \mathrm{C}$ & $260^{\circ} \mathrm{C}$ \\
\hline Film Thickness & $40 \mathrm{~nm}$ & $20 \sim 110 \mathrm{~nm}$ \\
\hline
\end{tabular}


中しないようにしてターゲット表面の損傷を防止した．膜の 評価は, 膜厚測定には段差膜厚計, 抵抗率などの電気的特性 には van der Pauw 法によるホール効果測定装置，透過率に は自記分光光度計を用いて測定を行った．膜厚と膜の反射率 の関係から反射防止効果が起こり, 透過率が $100 \%$ になるこ とがある。これはダブルビーム分光計のリファレンスにガラ ス基板，サンプルには成膜されたガラス基板を用いたからで ある、 また，表面・断面観察は電界放出型走査電子顕微鏡 (FE-SEM) および原子間力顕微鏡 $(\mathrm{AFM})$, 結晶構造分析 は X 線回折装置（XRD）で測定した.

\section{3. 実験結果及び考察}

膜厚 $40 \mathrm{~nm}$ 一定として基板温度 $200 \sim 300^{\circ} \mathrm{C}$ まで変化させ 実験を行った。Fig. 2 にそのときの電気的特性を示す。基 板温度の上昇に伴い抵抗率は減少し，基板温度 $260^{\circ} \mathrm{C}$ のとき 最も低い抵抗率 $2.61 \times 10^{-4} \Omega \cdot \mathrm{cm}$, ホール移動度 $27.7 \mathrm{~cm}^{2} / \mathrm{V}$ $\cdot \mathrm{s}$ ，キャリア密度 $8.64 \times 10^{20} \mathrm{~cm}^{-3}$ の良好な值が得られた. さらに基板温度を上昇させると抵抗率は増加した。この要因 として基板温度を上昇させたことにより，酸素欠陥が減少し キャリア密度の值が小さくなったためと考えられる。また, 移動度は基板温度 $260^{\circ} \mathrm{C}$ までは結晶性が向上したため増加し た。その結果として基板温度 $260^{\circ} \mathrm{C} て ゙$ 抵抗率が最も低い值に なった。

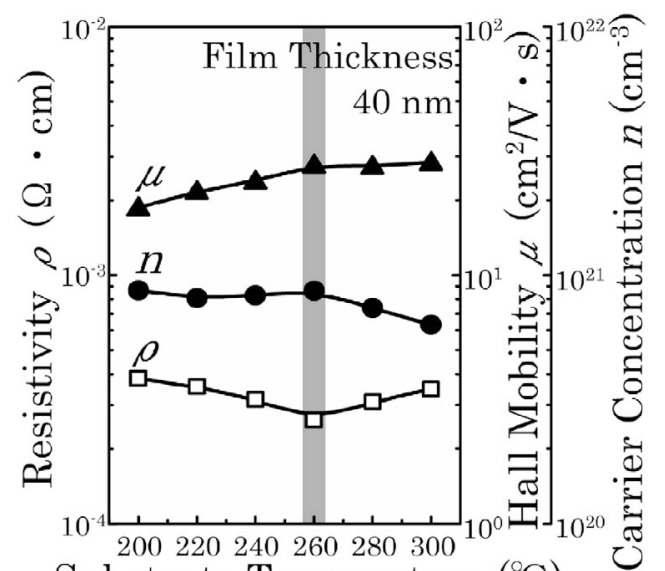

Substrate Temperature $\left({ }^{\circ} \mathrm{C}\right)$

Fig. 2 Substrate temperature dependence of electric properties for AZO films.

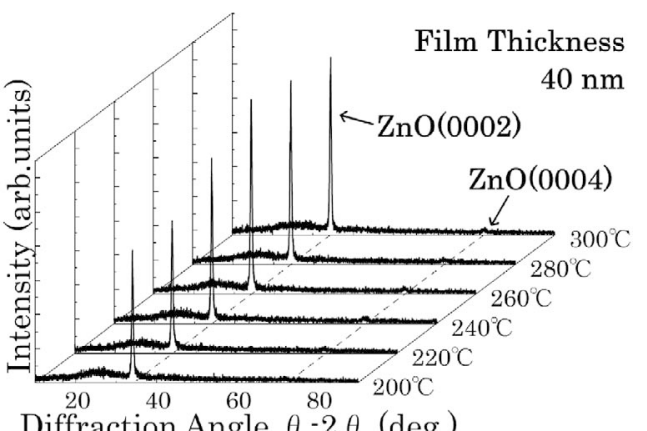

Diffraction Angle $\theta-2 \theta$ (deg.)

Fig. 3 Substrate temperature dependence of XRD spectra for AZO films.
Fig. 3 に基板温度依存性の X 線回折結果を示す. 基板温 度を上昇させると共に, $\mathrm{ZnO}(0002)$ 面の回折ピークが大き くなった。この要因として，基板温度を上昇させたことによ り結晶化が促進され結晶構造が改善されたと考えられる。こ れは Fig. 1に示す移動度の増加と一致している。

Fig. 4 に基板温度 $260^{\circ} \mathrm{C}$ で作製した膜の光学的特性を示 す. 可視光領域（波長 $400 \sim 700 \mathrm{~nm}$ ）に抢ける平均透過率は 全ての膜で $90 \%$ 以上を有しており，最も低い抵抗率を得た 基板温度 $260^{\circ} \mathrm{C}$ の時の平均透過率は $94.2 \%$ で，透明導電膜と して十分機能する值が得られた。

次に，基板温度を $260^{\circ} \mathrm{C}$ 一定として膜厚を $20 \sim 110 \mathrm{~nm}$ をで 変化させ実験を行った．Fig. 5 に電気的特性を示す．膜厚 が $20 \mathrm{~nm}$ の時, 抵抗率 $3.91 \times 10^{-4} \Omega \cdot \mathrm{cm}$ ，ホール移動度 22.4 $\mathrm{cm}^{2} / \mathrm{V} \cdot \mathrm{s}$, キャリア密度 $7.14 \times 10^{20} \mathrm{~cm}^{-3}$ の值が得られた。 さらに膜厚を増加させた場合，抵抗率が減少し，膜厚が 40 $\mathrm{nm}$ の時, $2.61 \times 10^{-4} \Omega \cdot \mathrm{cm}$ となり，膜厚が $110 \mathrm{~nm}$ の時に $2.14 \times 10^{-4} \Omega \cdot \mathrm{cm}$ となった．この主な要因としては，膜厚の 増加と共に結晶性が向上し，これが移動度の増加につながっ たためと考えられる。

Fig. 6 に膜厚依存性の X 線回折結果を示す. 膜厚を増加 させると共に， $\mathrm{ZnO}(0002)$ 面の回折ピークが大きくなっ た。また半値幅を求林とろ，膜厚 $20 \mathrm{~nm}, 40 \mathrm{~nm}, 110 \mathrm{~nm}$

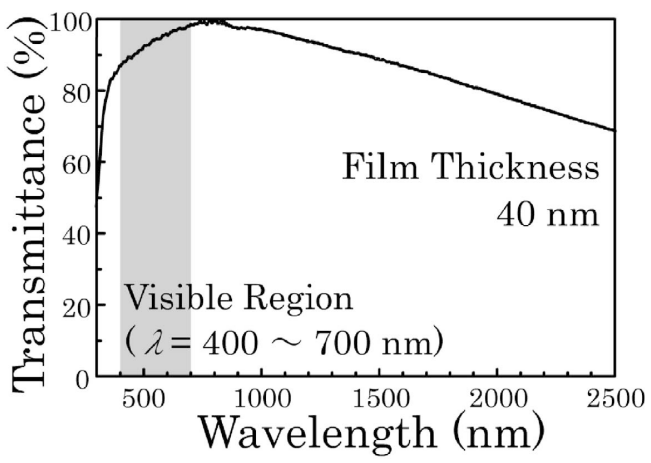

Fig. 4 Optical properties of $40 \mathrm{~nm}$-thick AZO film prepared at substrate temperature of $260^{\circ} \mathrm{C}$.

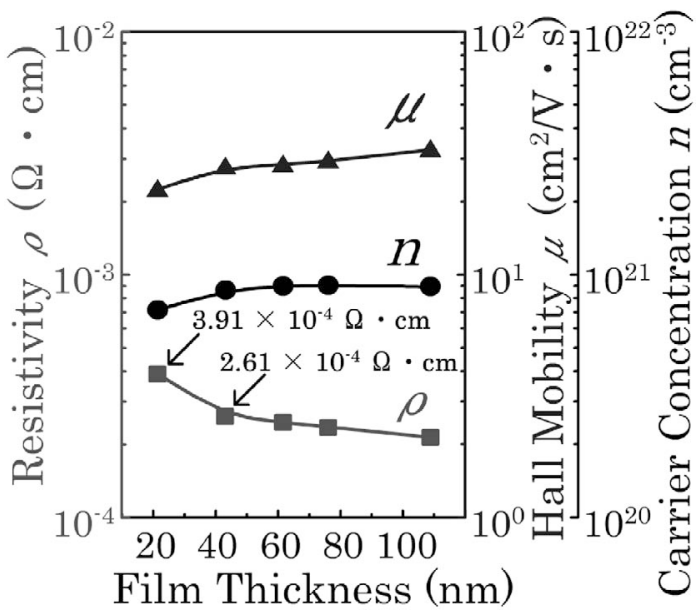

Fig. 5 Film thickness dependence of electric properties for AZO films. 


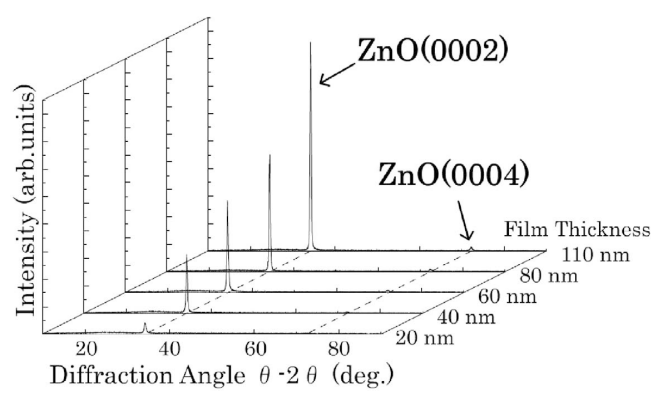

Fig. 6 Film thickness dependence of XRD spectra for AZO films.

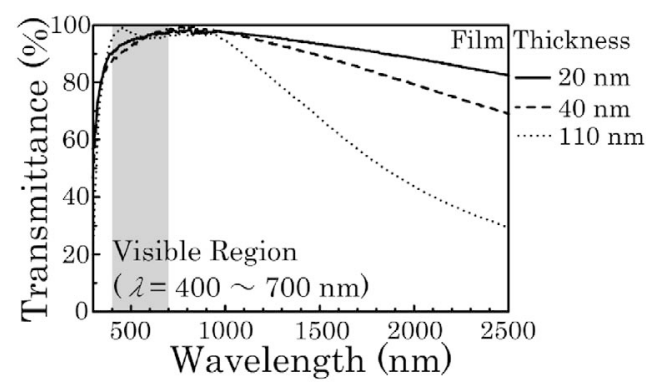

Fig. 7 Film thickness dependence of optical properties for AZO films.

でそれぞれ $0.5500^{\circ}, 0.3845^{\circ}, 0.2979^{\circ}$ であった。 また，Fig. 5 の膜厚増加に伴いホール移動度が増加しているために結晶 粒界などの散乱が少ないことが挙げられる．これらのことか ら結晶性が良くなっていると考えられる.

Fig. 7 に光学的特性の膜厚依存性を示す. 可視光領域

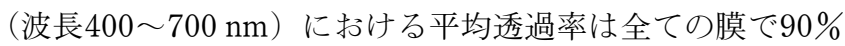
以上を有し, 膜厚 $20 \mathrm{~nm}$ で $95.1 \%, 40 \mathrm{~nm}$ で $94.2 \%, 110 \mathrm{~nm}$ で96.6\%の值が得られた. また, 長波長側の透過率が減少し た要因として，膜厚の増加とそれに伴う膜中に含まれる自由 電子の増加によるプラズマ共鳴現象が考えられる.

Fig. 8 に膜厚 $20 \mathrm{~nm}, 40 \mathrm{~nm}, 110 \mathrm{~nm}$ の FE-SEM 像およ び AFM 像を示す. SEM 像より全ての膜で，剥離や空隙な どは確認できず，膜厚 $20 \mathrm{~nm}$ でも島状構造は確認できなかっ た. 超薄膜領域で島状構造が確認できなかった要因として は，最適化された PLD 法を用いた成膜方法では，ターゲッ ト材料を原子レベルまで分解または溶解して基板に堆積させ ているため, 膜厚 $20 \mathrm{~nm}$ でも膜形成ができたと考えられる. また, 表面平均粗さ $R a$ は膜厚 $20 \mathrm{~nm}$ で $1.78 \mathrm{~nm}, 40 \mathrm{~nm}$ で $2.41 \mathrm{~nm}, 110 \mathrm{~nm}$ で3.19 nm で膜厚が増加すると共に粗くな った.これは結晶性の向上により, 結晶の粒径が大きくなっ たためと考えられる.

\section{4. まと め}

PLD 法でガラス基板上に AZO 透明導電膜を作製し，以下 の結果を得た。

1）基板温度 $260^{\circ} \mathrm{C}$, 膜厚 $40 \mathrm{~nm}$ の時, 最も低い抵抗率

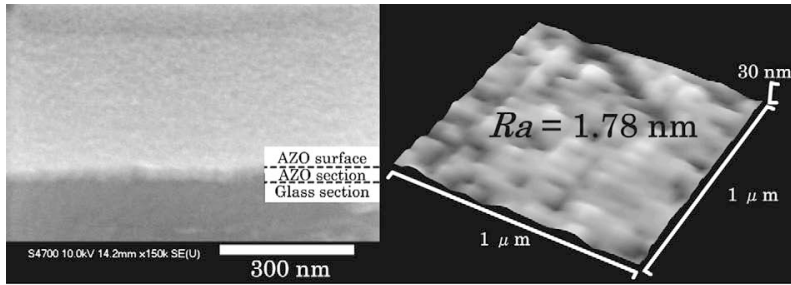

(a) $20 \mathrm{~nm}$

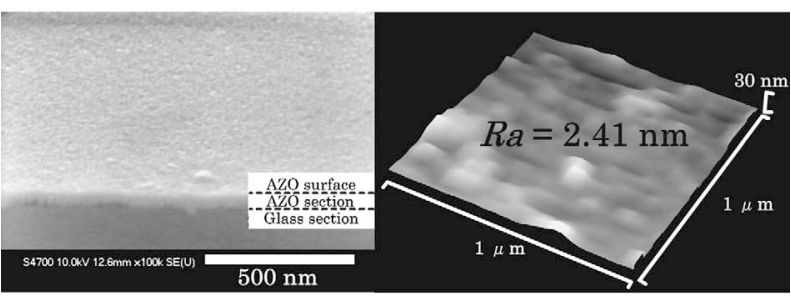

(b) $40 \mathrm{~nm}$

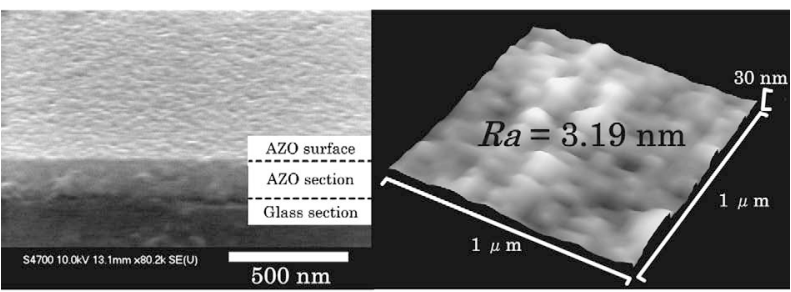

(c) $110 \mathrm{~nm}$

Fig. 8 FE-SEM and AFM images of AZO films with (a) 20 nm-thick, (b) $40 \mathrm{~nm}$-thick, (c) $110 \mathrm{~nm}$-thick.

$2.61 \times 10^{-4} \Omega \cdot \mathrm{cm}$ の良好な值が得られた。

2）超薄膜領域の膜厚 $20 \mathrm{~nm}$ においても，抵抗率 $3.91 \times$ $10^{-4} \Omega \cdot \mathrm{cm}$ の低抵抗な $\mathrm{AZO}$ 透明導電膜が得られた.

3）いずれの薄膜も可視光領域に打ける平均透過率は 90 \%以上を有していた.

4） FE-SEM および AFM により，超薄膜領域（膜厚20 $\mathrm{nm})$ に括いて島状構造は確認できず，また表面平均粗さ $R a$ は1.78 nmの平坦な膜が得られた.

\section{〔文献〕}

1) A. Suzuki, T. Matsushita, T. Aoki, Y. Yoneyama and M. Okuda: Jpn. J. Appl. Phys., 38 (1999) L71.

2) 南内 嗣: 応用物理 75, 1218 (2006).

3) T. Yamada, A. Miyake, S. Kishimoto, H. Makino, N. Yamamoto and T. Yamamoto: Appl. Phys. Lett., 91 (2007) 051915.

4) A. Suzuki, T. Matsushita, Y. Sakamoto, N. Wada, T. Fukuda, H. Fujiwara and M. Okuda: Jpn. J. Appl. Phys., 35 (1996) 5457.

5) Holmelund. E, Schou. J, Thestrup. B, Tougaard. S, Johnson. E, Nielsen. M. M, Applied Physics A: Materials Science \& Processing. 2004. Vol. 79 Issue 4-6. p1137.

6) H. Agura, Y. Takase, A. Nakamura, Y. Higashimura, A. Suzuki, T. Aoki, T. Matsushita, M. Okuda: Shinku, 49 (2006) 562.

7) H. Agura, K. Uehara, K. Takahashi, A. Suzuki, T. Aoki, T. Matsushita, M. Okuda: Shinku, 49 (2006) 377.

8) Y. Takase, H. Agura, A. Nakamura, Y. Higashimura, A. Suzuki, T. Aoki, T. Matsushita, M. Okuda: Shinku, 49 (2006) 153.

9) A. Suzuki: Shinku, 50 (2007) 118. 